\title{
O PROJETO DE EDIFÍCIOS HABITACIONAIS CONSIDERANDO A NORMA BRASILEIRA DE DESEMPENHO: ANÁLISE APLICADA PARA AS VEDAÇÕES VERTICAIS
}

Residential building design considering the brazilian performance standard: analyses to wall partition

\author{
Luciana Alves Oliveira ${ }^{i}$ e-mail | CV Lattes \\ Claudio Vicente Mitidieri Filho ${ }^{i i}$ e-mail | CV Lattes
}

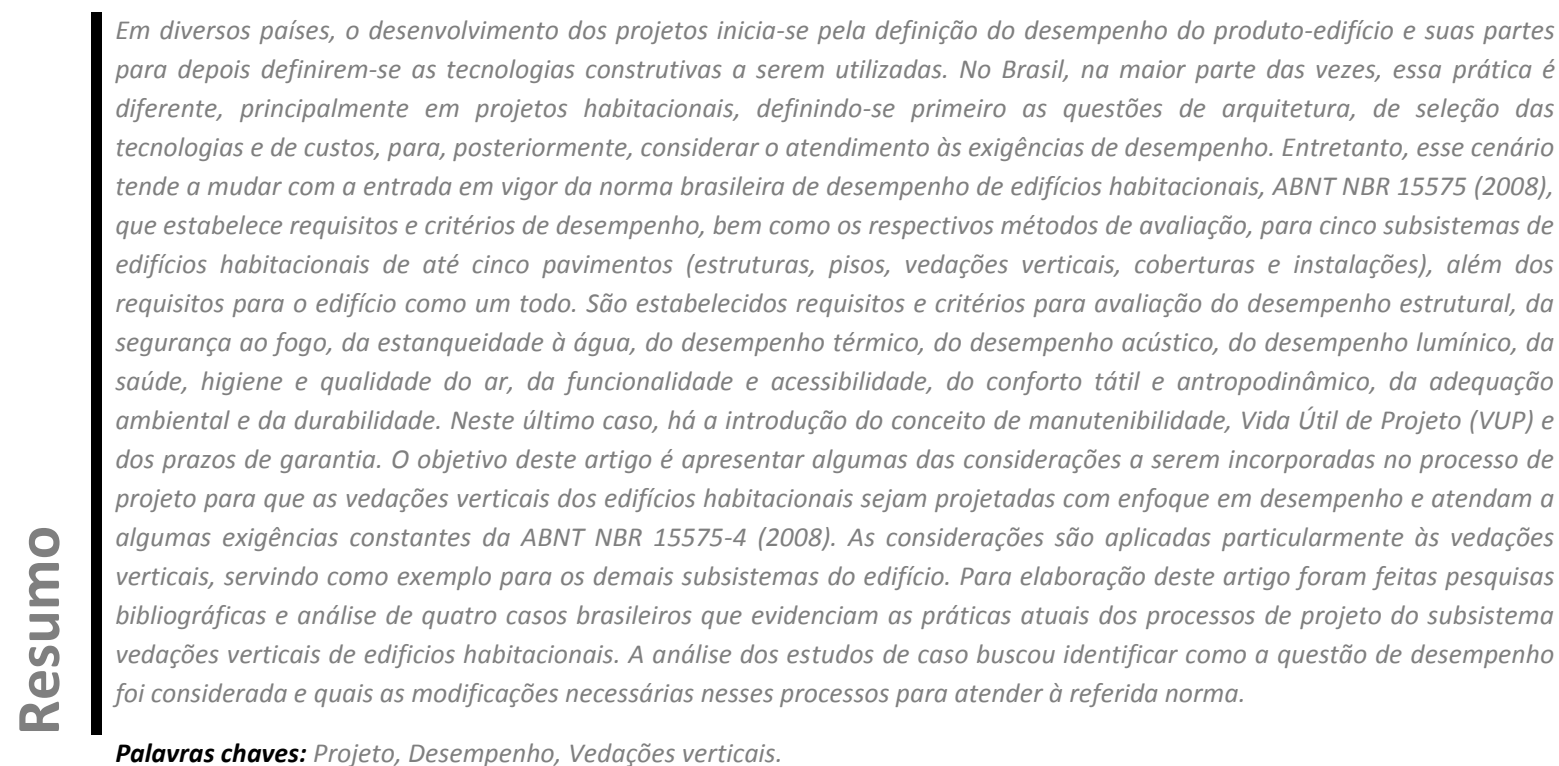

Palavras chaves: Projeto, Desempenho, Vedações verticais.

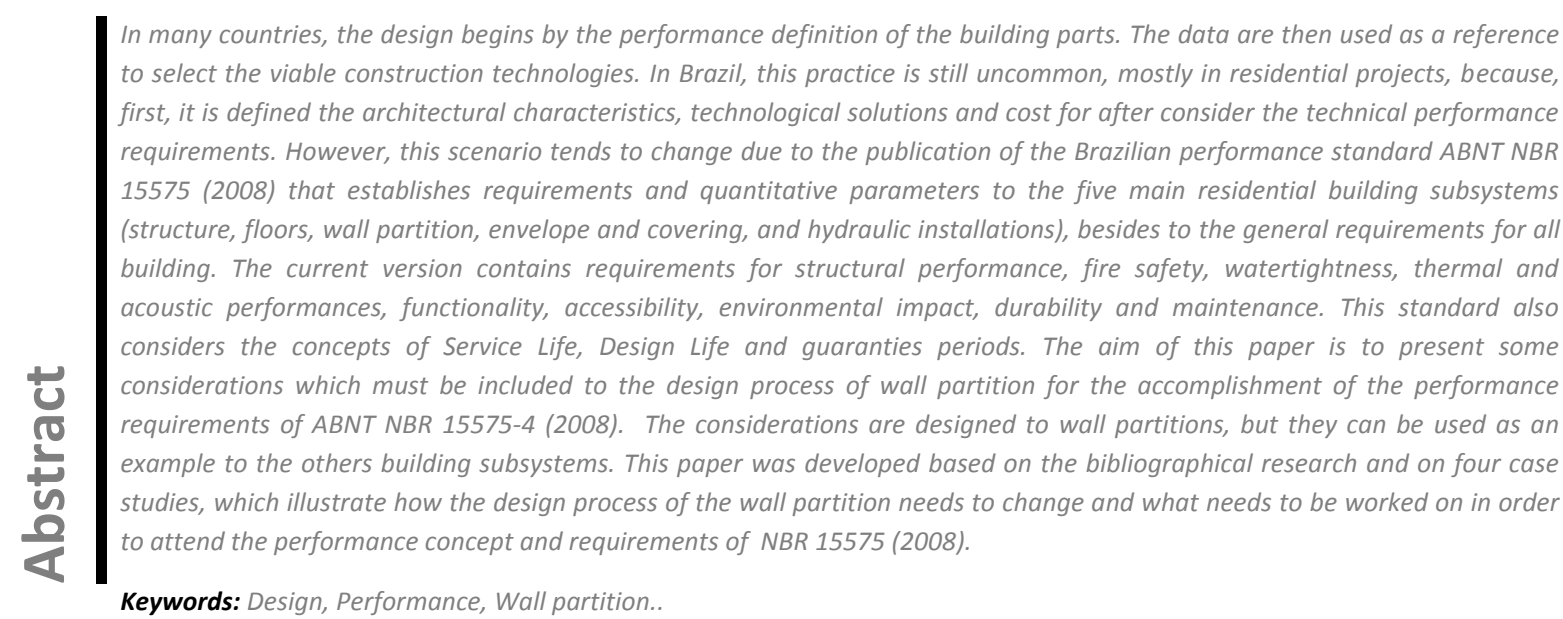




\section{INTRODUÇAO}

A tendência atual é que os projetos dos edifícios sejam concebidos com enfoque em desempenho, isto é, desde a fase de concepção, nas definições das exigências do programa de necessidades, os requisitos de desempenho já são levados em conta.

Em alguns países, como França, Canadá e Japão, o desenvolvimento dos projetos inicia-se pela definição do desempenho do produto-edifício e dos seus subsistemas para, posteriormente, definirem-se as tecnologias construtivas a serem adotadas. Especificamente na França alguns requisitos de desempenho relativos à segurança contra incêndio (CABINET CASSO et Cia., 2002 e 2004), desempenho térmico (FRANCE RT 2005, 2006) e desempenho acústico (MEISSER, 2005) são exigências constantes da legislação. Assim, obrigatoriamente, os projetos são concebidos para atender a esses requisitos legais, além dos requisitos estabelecidos pelo incorporador.

Cada vez mais a prática de projetar com enfoque em desempenho deve ser incorporada ao processo de projeto, principalmente em razão das crescentes preocupações a respeito da durabilidade e da sustentabilidade. De fato, segundo as diretrizes apresentadas no documento UNEP/TIE (2007), um produto para atender às exigências de sustentabilidade deve ser pensado estrategicamente, sendo todas as etapas e atividades do processo de produção do edifício direcionadas para atender aos mesmos objetivos de atendimento a requisitos de desempenho e sustentabilidade desde o início do processo.

Além disso, o conceito de desenvolvimento sustentável incita a idéia de projetar o edifício não somente para a construção e o uso, mas também para sua fase final, incluindo o conceito de desconstrução, desmontabilidade e reciclabilidade; portanto, incluindo o conceito de Vida Útil de Projeto e Custo Global. Para Hernandez-Moreno (2010) o processo de projeto do edifício tem cinco fases: 1) concepção (pré-projeto), fase na qual as premissas e exigências são definidas, principalmente a respeito de desempenho e durabilidade; 2) desenvolvimento (projetos executivos), fase na qual as definições são traduzidas em desenhos e especificações; 3) construção; 4) manutenção; e 5) fase final da vida útil do edifício, sendo que previamente é definido como a vida do edifício termina (desconstrução, desmontabilidade e reciclabilidade). Diversas organizações vêm desenvolvendo normas para regulamentar a vida útil de projeto (VUP) do edifício e suas partes (ISO 15686-1, 2000 e CSA S478-95, 2001). Tais normas apresentam métodos para que os projetos sejam concebidos visando o atendimento da VUP e, portanto, as exigências de desempenho, relativas à segurança, habitabilidade e sustentabilidade, que englobam as questões de durabilidade.

No Brasil, na maior parte dos casos, o desenvolvimento dos projetos não considera as questões de desempenho, principalmente em projetos habitacionais, nos quais são definidas inicialmente as questões de arquitetura e de seleção das tecnologias, para, posteriormente e nem sempre, considerar $o$ atendimento às exigências de desempenho (MELHADO, 2001; AQUINO, 2005, ONO, 2007).

Entretanto, esse cenário tende a mudar com a entrada em vigor da norma brasileira ABNT NBR 15575 (2008), partes 1 a 6 - "Desempenho de edifícios habitacionais de até 05 pavimentos". Essa norma estabelece requisitos (exigências qualitativas) e critérios (exigências quantitativas) de desempenho para cinco subsistemas dos edifícios habitacionais de até cinco pavimentos (estruturas, pisos, vedações verticais, coberturas e instalações), além de requisitos gerais para o edifício como um todo, em sua primeira parte. São estabelecidos requisitos e critérios para avaliação de diversas exigências do usuário, como: desempenho estrutural; segurança ao fogo; estanqueidade à água; desempenho térmico; desempenho acústico; segurança no uso e operação; desempenho lumínico; saúde, higiene e qualidade do ar; funcionalidade e acessibilidade, conforto tátil e antropodinâmico; adequação ambiental; e durabilidade e manutenibilidade. No caso da durabilidade, foram introduzidos importantes conceitos, como Vida Útil de Projeto (VUP) e prazos de garantia, que, apesar de indicações ainda não normativas, podem constar no projeto e no manual de uso, operação e manutenção do edifício. Além dos requisitos e critérios são também estabelecidos os métodos de avaliação a serem empregados para verificação desses critérios. Essa norma é direcionada tanto para tecnologias construtivas convencionais quanto para tecnologias inovadoras. Portanto, os projetistas de arquitetura e de todos os demais subsistemas integrantes do edifício, os consultores, os construtores e os fornecedores terão que modificar suas práticas atuais de desenvolvimento de projetos. Já há previsão na versão da norma de 2008 de que vários critérios podem ser aplicados a qualquer edifício habitacional, independentemente de sua altura, como desempenho térmico, acústico e durabilidade, por exemplo. 
O objetivo deste artigo é apresentar alguns aspectos a serem incorporados ao processo de projeto, para que as vedações verticais dos edifícios habitacionais sejam projetadas com enfoque em desempenho e atendam a exigências constantes da norma ABNT NBR 15575-4 (2008). Não há neste artigo a preocupação nem a pretensão de avaliar as tecnologias, mas somente de verificar como os aspectos de desempenho são considerados na etapa de projeto. 0 fato de não se considerar os aspectos de desempenho na fase de projeto não significa, necessariamente, que o sistema não atenda determinados critérios de desempenho; porém, se o projeto já for conduzido à luz do conceito de desempenho, a seleção das alternativas tecnológicas e a definição do desempenho do edifício já são feitas nesta etapa de produção do edifício ou do empreendimento. Optou-se por tratar do desenvolvimento de projetos para o subsistema de vedações verticais em razão do crescente número de inovações tecnológicas empregadas nesse subsistema e pela influência que os elementos das vedações, sejam externos ou internos, exercem no processo de produção de um edifício, relacionada ao custo, à definição da logística e do planejamento da obra, até o comportamento do edifício em uso. No Brasil (Construção Mercado, 2006; Construção Mercado 2008) e em outros países as vedações verticais representam aproximadamente $20 \%$ do custo total da construção do edifício (Rivard et al, 1999).

A apresentação das informações e dos dados desse artigo divide-se em quatro partes:

- $\quad$ Método de pesquisa e análise;

- $\quad$ Apresentação e análise dos estudos de caso;

- Modificações a serem incorporadas no processo de desenvolvimento de projetos visando o atendimento da NBR 15575 (2008);

- $\quad$ Considerações finais

\section{MÉTODO DE PESQUISA E ANÁLISE}

Para elaboração desse artigo foram feitas pesquisas bibliográficas e estudos de caso. As pesquisas bibliográficas concentraram-se em questões relativas à gestão do processo de projeto, considerando os aspectos de sustentabilidade e desempenho, às leis e normas técnicas existentes no Brasil e em outros países de referência relativas ao desempenho do edifício.

Os estudos de caso são explanatórios ${ }^{1}$, pois foram feitos para evidenciar as práticas de projetos atuais, buscando-se identificar como a questão de desempenho foi considerada e quais as modificações necessárias nesses processos para atender a norma NBR 15575 (2008).

Foram realizados quatro estudos de caso (A, B, C e D) em empreendimentos destinados a habitações de interesse social, que foram construídos durante os anos de 2008, 2009 e 2010. Visando limitar o escopo do trabalho e facilitar a coleta de informações, as análises dos estudos de caso foram concentradas no subsistema de vedação vertical. Em todos os estudos de caso as vedações verticais tinham função estrutural. No estudo de caso A, a tecnologia de parede adotada era formada por quadros estruturais e chapas delgadas. No estudo de caso $B$, painéis pré-moldados de

\footnotetext{
${ }^{1}$ Segundo Yin (1981), se um estudo de caso objetiva explicar e demonstrar fatos, ele é classificado como explanatório
}

concreto armado. No estudo de caso C, painéis tipo sanduiche. No estudo de caso D, parede de alvenaria estrutural de blocos de concreto.

Os estudos foram realizados na fase de projeto, sendo que as seguintes atividades foram desenvolvidas: análise dos documentos gerados no processo de projeto das vedações verticais e entrevista com os principais agentes desse processo. Para uniformizar a coleta e análise de informações desses estudos foram feitos roteiros aplicados a cada estudo, para identificar informações do processo de projeto que influenciam todo o resultado do projeto e da obra no que diz respeito ao desempenho. Portanto, foram consideradas relevantes as informações referentes:

- à tecnologia construtiva adotada e sua relação, na concepção do projeto, com o atendimento das exigências de desempenho;

- à seleção da tecnologia e seu detalhamento no projeto;

- à verificação dos critérios de desempenho na fase de projeto;

- $\quad$ às exigências contratuais definidas para os fornecedores, referentes ao fornecimento de informações técnicas sobre o desempenho do produto.

Também foi considerado relevante avaliar em qual etapa do processo de projeto as questões de desempenho, quando tratadas, foram 
consideradas, isto porque se discutidas e analisadas somente na etapa de detalhamento do projeto, quando todas as definições de produto tiverem sido feitas, pouca qualidade será agregada ao produto final.

A ABNT NBR 15575 (2008) estabelece critérios de desempenho para vários subsistemas dos edifícios (estrutura, piso, vedações verticais, cobertura e instalações), independentemente da tecnologia construtiva adotada. Por isso, considera-se que a seleção da tecnologia é um dos primeiros pontos a serem analisados, pois a avaliação de desempenho é feita especificamente para uma tecnologia construtiva, considerando sua aplicação, seja como vedação vertical, cobertura ou outro subsistema.

\section{APRESENTAÇÃO E ANÁLISE DOS ESTUDOS DE CASOS}

As tecnologias construtivas adotadas nos estudos de casos A, B e C não têm norma técnica prescritiva para balizamento do desenvolvimento dos projetos e da execução de obras. Somente no estudo D adotou-se tecnologia considerada convencional, isto é, que conta com norma técnica prescritiva.

Nos estudos A, B e C as respectivas tecnologias foram selecionadas pelo incorporador e construtor, em razão da alta produtividade que poderia ser conseguida durante a construção, reduzindo significativamente o prazo da obra. No caso $D$, a tecnologia foi definida também pelo incorporador e construtor, pelo conhecimento consolidado da tecnologia no setor e porque a construtora possuía mão-de-obra especializada para a sua execução. Assim, nos quatro casos, na fase de concepção e definição do programa de necessidades, além das exigências de desempenho estrutural explicitadas nos casos A, $B$ e D, nenhuma outra exigência de desempenho foi explicitada. Haviam previsões de questões relativas à produtividade e aos custos. No caso D, em particular, não foram definidos e discutidos requisitos de desempenho nas etapas preliminares de projeto, porque os agentes participantes consideravam que, pelo fato da tecnologia ser consolidada, atenderia a todas as exigências de desempenho.

O detalhamento técnico dos projetos, nos casos A e B, foi desenvolvido pela empresa construtora, na posição também de proponente e fornecedora da tecnologia. Todavia, esse detalhamento não previa detalhes para as soluções de interface entre componentes e elementos tais como juntas entre vedação vertical e pisos internos e externos, e juntas entre elementos da vedação vertical. No caso C não havia ainda o detalhamento do projeto. No caso D o detalhamento do projeto foi feito pelo projetista de arquitetura, porém sem explicitar alguns fatores técnicos que interferem no desempenho das vedações verticais quando se adota alvenaria estrutural. Alguns desses fatores referem-se à compatibilização da dimensão das paredes com a modulação dos blocos de concreto, definição da espessura do bloco e do revestimento da parede em função de exigências de desempenho acústico e térmico, além das exigências de resistência ao fogo.

Com relação às exigências de desempenho consideradas em projeto, pode-se dizer que nos casos A e B somente foram explicitadas exigências relativas ao desempenho estrutural. No caso $C$ não foram explicitadas exigências de desempenho. No caso $\mathrm{D}$ foram definidas exigências de desempenho estrutural, de estanqueidade à água e de isolação sonora somente a partir do desenvolvimento do projeto básico. Outros aspectos, relacionados à resistência ao fogo, por exemplo, foram considerados como atendidos, em razão da tecnologia ser considerada convencional, porém os critérios e os métodos de comprovação de atendimento não foram formalizados.

Em nenhum dos casos foi observada em projeto a formulação de requisitos e critérios relativos à durabilidade, particularmente com definições de Vida Útil de Projeto (VUP), aspectos de manutenibilidade e prazos de garantia.

Quanto ao relacionamento com os fornecedores, não foram constatadas em projeto especificações técnicas e exigências de fornecimento de informações de desempenho para os fornecedores de tecnologias, materiais e/ou componentes, nem alusão à necessidade de um contrato de fornecimento de insumos com base em desempenho.

O Quadro 1 resume as principais informações coletadas nos estudos de caso, relevantes para demonstrar como o desempenho foi considerado no processo de projeto. 
Quadro 1 - Resumo das informações coletadas nos estudos de caso

\begin{tabular}{|c|c|c|c|c|}
\hline \multirow{2}{*}{$\begin{array}{c}\text { INFORMAÇÕES } \\
\text { COLETADAS }\end{array}$} & \multicolumn{4}{|c|}{ ESTUDOS DE CASO } \\
\hline & $\mathrm{A}$ & B & $\mathrm{C}$ & $\mathrm{D}$ \\
\hline $\begin{array}{c}\text { Tecnologia } \\
\text { selecionada para as } \\
\text { vedações verticais }\end{array}$ & $\begin{array}{l}\text { Quadros pré- } \\
\text { fabricados }\end{array}$ & $\begin{array}{l}\text { Elementos pré- } \\
\text { fabricados de- } \\
\text { concreto }\end{array}$ & $\begin{array}{l}\text {-Painéis } \\
\text { sanduiche }\end{array}$ & $\begin{array}{c}\text { Paredes de } \\
\text { alvenaria } \\
\text { estrutural } \\
\end{array}$ \\
\hline $\begin{array}{c}\text { Responsáveis pela } \\
\text { adoção da } \\
\text { tecnologia- } \\
\text { justificativa }\end{array}$ & $\begin{array}{l}\text { Incorporador - } \\
\text { produtividade } \\
\text { durante a } \\
\text { construção }\end{array}$ & $\begin{array}{l}\text { Comprador - } \\
\text { produtividade e } \\
\text { qualidade ofertada } \\
\text { pelo proponente }\end{array}$ & $\begin{array}{l}\text { Incorporadore } \\
\text { construtor - } \\
\text { tecnologia } \\
\text { estrangeira }\end{array}$ & $\begin{array}{c}\text { Incorporador - } \\
\text { conhecimento da } \\
\text { tecnologia e mão- } \\
\text { de-obra } \\
\text { especializada } \\
\end{array}$ \\
\hline $\begin{array}{c}\text { Relação da } \\
\text { tecnologia e as } \\
\text { exigências de } \\
\text { desempenho - } \\
\text { desempenho } \\
\text { estrutural, } \\
\text { segurança ao fogo, } \\
\text { habitabilidade e } \\
\text { sustentabilidade }\end{array}$ & $\begin{array}{l}\text { No programa de } \\
\text { necessidades foi } \\
\text { considerado o } \\
\text { desempenho } \\
\text { estrutural }\end{array}$ & $\begin{array}{l}\text { No programa de } \\
\text { necessidades } \\
\text { definiu-se a } \\
\text { preocupação com a } \\
\text { isolação sonora de } \\
\text { paredes, porém } \\
\text { não foram } \\
\text { definidos critérios }\end{array}$ & $\begin{array}{l}\text { No programa de } \\
\text { necessidades não } \\
\text { foram definidos } \\
\text { os critérios de } \\
\text { desempenho }\end{array}$ & $\begin{array}{c}\text { Desempenho não } \\
\text { foi discutido nas } \\
\text { etapas } \\
\text { preliminares, por } \\
\text { considerar que a } \\
\text { tecnologia já é } \\
\text { consolidada }\end{array}$ \\
\hline $\begin{array}{l}\text { Detalhamento do } \\
\text { projeto }\end{array}$ & $\begin{array}{l}\text { Falta de detalhes } \\
\text { para soluções de } \\
\text { interface }\end{array}$ & $\begin{array}{l}0 \text { detalhamento } \\
\text { construtivo foi } \\
\text { feito pela } \\
\text { construtora/ } \\
\text { proponente }\end{array}$ & $\begin{array}{l}\text { Projeto ainda } \\
\text { sem } \\
\text { detalhamento }\end{array}$ & $\begin{array}{l}\text { Detalhamento do } \\
\text { projeto de } \\
\text { arquitetura, sem } \\
\text { explicitar fatores } \\
\text { técnicos que } \\
\text { interferem no } \\
\text { desempenho das } \\
\text { vedações verticais }\end{array}$ \\
\hline $\begin{array}{c}\text { Verificação de } \\
\text { critérios de } \\
\text { desempenho na fase } \\
\text { de projeto }\end{array}$ & $\begin{array}{c}\text { Somente } \\
\text { exigências de } \\
\text { desempenho } \\
\text { estrutural - sem } \\
\text { discussão de } \\
\text { questões } \\
\text { relativas a } \\
\text { estanqueidade à } \\
\text { água e } \\
\text { durabilidade }\end{array}$ & $\begin{array}{c}\text { O projeto de } \\
\text { estrutura não } \\
\text { atendia } \\
\text { integralmente as } \\
\text { diretrizes; } \\
\text { desempenho } \\
\text { acústico atendido, } \\
\text { não } \\
\text { intencionalmente }\end{array}$ & $\begin{array}{l}\text { Sem verificação } \\
\text { na fase de projeto }\end{array}$ & $\begin{array}{c}\text { Foram } \\
\text { consideradas } \\
\text { (projeto básico) } \\
\text { exigências de } \\
\text { desempenho } \\
\text { estrutural, de } \\
\text { estanqueidade à } \\
\text { água e de isolação } \\
\text { sonora. Outros } \\
\text { aspectos foram } \\
\text { considerados } \\
\text { como atendidos }\end{array}$ \\
\hline $\begin{array}{c}\text { Exigências } \\
\text { contratuais para } \\
\text { fornecedores } \\
\text { referentes a } \\
\text { desempenho do } \\
\text { produto } \\
\end{array}$ & \multicolumn{4}{|c|}{$\begin{array}{c}\text { Não foram feitas em projeto especificações técnicas e exigências de desempenho } \\
\text { para os fornecedores de tecnologias, de materiais e/ou componentes, nem alusão } \\
\text { à necessidade de um contrato de fornecimento de insumos com base em } \\
\text { desempenho }\end{array}$} \\
\hline
\end{tabular}

Conforme pode ser observado, em três dos casos estudados a tecnologia construtiva adotada não possui normalização técnica de referência para o desenvolvimento dos projetos e para a execução de obras, o que torna a fase de desenvolvimento de projetos ainda mais complexa. É nesta fase que devem ser analisadas todas as características, condições de uso e eventuais limitações da tecnologia, de forma a incorporar tais informações ao projeto, visando obter um desempenho potencial adequado para o edifício ao longo da Vida Útil de Projeto, conforme sugerido na ABNT NBR 15575-1(2008). Se uma tecnologia é considerada inovadora e não há parâmetros de desempenho divulgados, é necessária a realização de ensaios e análises específicas para identificar e conhecer esses parâmetros. Além de ensaios e análises, o projetista responsável pelo detalhamento do projeto deve levar em conta as várias interfaces existentes entre os diversos componentes, elementos e subsistemas, tentando identificá-las e resolvê-las. 
Outra questão importante refere-se a "quem" selecionou a tecnologia e "por que"? Na maioria dos casos estudados a tecnologia construtiva foi selecionada pelo construtor e incorporador. Os requisitos considerados na seleção das tecnologias foram de custo e prazo, não sendo explicitadas exigências de desempenho, com exceção das exigências de desempenho estrutural. A preocupação fundamental refere-se às exigências de atendimento aos estados limite último e de serviço, sem considerar questões relativas à segurança no uso, como resistência a impactos, por exemplo.

No caso $D$ foram apontadas exigências de isolação sonora, tendo sido incorporados ao projeto resultados de ensaios, mostrando que a parede atende ao mínimo previsto na NBR 15.575-4, para isolação a ruídos aéreos entre ambientes. A definição da espessura total da parede considerou questões de ordem construtiva e de desempenho estrutural, e, consequentemente, os resultados de isolação foram adequados.

No caso C não foram explicitados requisitos de desempenho nas etapas preliminares de projeto, pois, havia, talvez, o pressuposto de que, por ser a tecnologia conhecida e consolidada fora do Brasil, já haveria o atendimento das exigências de desempenho específicas para o Brasil. Essa pressuposição, entretanto, nem sempre é válida, pois, nem sempre uma tecnologia adequada para as exigências de outros países também é adequada ao Brasil.
No empreendimento $\mathrm{D}$, a tecnologia selecionada é considerada convencional no Brasil, sendo considerado este fato como justificativa para não explicitar critérios de desempenho no projeto. Uma vez que a tecnologia é consolidada, considerou-se que o atendimento a tais critérios já estava resolvido, o que nem sempre é adequado, pois, o desempenho depende de diversos fatores, como espessura da parede adotada, interfaces com demais componentes e elementos construtivos, além de disposições definidas em projeto. Para avaliar se uma tecnologia convencional atende aos critérios da norma NBR 15575 (2008), pressupondo-se que já são conhecidos os dados sobre seu potencial desempenho, o que nem sempre acontece, podese fazer uma análise comparativa dos dados de projeto com os dados de referência disponíveis; também são possíveis análises do emprego conjunto de diversos componentes construtivos, como, por exemplo, a análise da isolação sonora de uma fachada de dormitório, considerando a isolação sonora da parede e da janela.

Como observado em todos os casos estudados, a consideração de requisitos e critérios de desempenho em projeto ainda não é uma prática rotineira, nem tampouco dos métodos de avaliação que comprovem o atendimento das exigências definidas, com exceção daqueles relativos ao desempenho estrutural. Requisitos de durabilidade e manutenibilidade não foram explicitados em projeto.

\section{MODIFICAÇÕES A SEREM INCORPORADAS NO PROCESSO DE PROJETO}

Os estudos de caso mostram que mudanças precisam ser incorporadas às práticas atuais de desenvolvimento de projetos para que o edifício e seus sistemas, como as vedações verticais, possam ser projetados com o enfoque em desempenho e atender aos critérios definidos na ABNT NBR 15575 (2008) ou norma sucedânea.

Como sugestões, algumas considerações são elencadas a seguir para serem incorporadas nas práticas de projetos atuais, observando, entretanto, que tais considerações são indicadas principalmente para o processo de projeto das vedações verticais, em razão dos resultados dos estudos de casos que basearam este artigo, mas podem ser utilizadas como exemplo para os demais subsistemas do edifício.

- $\quad$ Os agentes do processo de produção do edifício (incorporadores, projetistas, construtores e fabricantes de produtos) precisam conhecer em profundidade os requisitos e os critérios de desempenho aplicáveis a cada empreendimento habitacional específico, mesmo porque alguns critérios podem ser associados a três níveis ( mínimo, intermediário e superior);

- $\mathrm{Na}$ definição do programa de necessidades e no desenvolvimento dos estudos preliminares, antes da definição da tecnologia construtiva, é preciso definir quais os requisitos que deverão ser atendidos pelo empreendimento e quais as tecnologias construtivas disponíveis que apresentam potencial para atender a esses requisitos. A seleção da tecnologia deve considerar uma ponderação entre benefícios técnicos, de custo e de prazo, conforme propõe SOUZA (2003). Nesta etapa, projetistas especialistas, fornecedores e construtores devem integrar a equipe técnica de projeto. 
- Quando a tecnologia a ser selecionada é considerada inovadora, é necessário identificar fornecedor que já tenha feito sua avaliação técnica ou esteja disposto a realizá-la, de forma a disponibilizar ao projetista, ao incorporador e ao construtor os parâmetros de desempenho potencial. Tecnologias inovadoras que apresentam Documento de Avaliação Técnica (DATec), no SiNAT2 ${ }^{2}$, dispõem de informações técnicas. Além disso, deve ser realizado um estudo sobre as possibilidades e as dificuldades de atendimento aos critérios de desempenho, particularmente se houver interesse da adoção de critérios acima do nível mínimo, quais sejam, intermediário ou superior. Na França, assim como em outros países, essas avaliações já são realizadas há muito tempo, gerando documentos como o ATEC (Avis Technique - Apreciação técnica) e o ATEX (Apreciação Técnica de Experimentação) (Vigan, 1993). Alguns pesquisadores, como Becker (2002), mostram metodologias de avaliação técnica para sistemas construtivos inovadores.

- Se a tecnologia selecionada é considerada convencional, é necessária a construção de um banco de dados com todas as informações a respeito do seu desempenho potencial, de problemas e soluções de interfaces conhecidos. Com esse banco de dados é possível realizar uma comparação entre os critérios previstos na norma de desempenho e os índices relativos ao desempenho de determinada tecnologia. Uma possibilidade é a adoção de dados e informações que poderiam estar disponíveis em Códigos de Práticas (CLETO et al., 2011);

- Os critérios de desempenho (parâmetros quantitativos) devem ser analisados e considerados já no desenvolvimento do anteprojeto, isto é, na fase inicial de desenvolvimento dos projetos, conforme exposto por OLIVEIRA (2009).

- As exigências de desempenho estabelecidas para o empreendimento podem ser formalizadas em documentos técnicos, como cadernos técnicos ou regras de boas práticas, que integram os contratos. Definições de "como" e "por quem" deverá ser feita a comprovação do atendimento a essas exigências também devem constar desses documentos. As ferramentas/métodos de controle a serem adotados, tanto do gestor quanto dos próprios fornecedores devem constar de contratos. Por

2 SINAT - Sistema Nacional de Avaliação Técnica de Produtos Inovadores, vinculado ao PBQP-H, Ministério das Cidades. Disponível em:〈http://www2.cidades.gov.br/pbqp-h/projetos.php> exemplo, um fornecedor de painéis prémoldados precisa saber, pois consta do seu contrato, quais informações técnicas ele precisará apresentar. Um fornecedor de blocos cerâmicos para construção de alvenaria de vedação, segundo regras contratuais, precisa apresentar ao projetista e ao construtor, além das características dos blocos, as características da parede com relação à isolação sonora e resistência ao fogo, por exemplo. Portanto, nos contratos com fornecedores é recomendável que conste as exigências de desempenho que tal produto precisa atender e a forma como esse fornecedor comprovará tal atendimento.

- 0 fornecedor da tecnologia (denominado muitas vezes pelo mercado como fornecedor de sistema construtivo) precisa apresentar, além das informações de desempenho do seu produto, um detalhamento do projeto mostrando as soluções de interfaces, restrições ou limitações de uso do produto, procedimento de execução, entre outros. 0 procedimento de execução e suas formas de controle têm grande interferência na qualidade do produto final, ou seja, do edifício habitacional. Uma tecnologia construtiva pode apresentar bom potencial para atender às exigências de desempenho, porém, se mal executada pode não apresentar o comportamento previsto em projeto.

- Os principais requisitos de desempenho estabelecidos na ABNT NBR 15575-4 (2008) para as vedações verticais a serem considerados no projeto são:

o desempenho estrutural (considerando os estados limites último e de serviço, a resistência a impactos de corpo mole e corpo duro, a resistência a solicitações transmitidas por portas e a fixação de peças suspensas);

o segurança ao fogo ( reação ao fogo dos materiais de acabamento e revestimento - índice de propagação de chamas, densidade de fumaça - e resistência ao fogo das paredes estruturais e de compartimentação);

o estanqueidade à água (estanqueidade da fachada, considerando juntas entre componentes construtivos e estanqueidade dos próprios componentes; estanqueidade à água ascendente das fundações e do solo; estanqueidade à água de uso e lavagem de ambientes molháveis);

o desempenho acústico (isolação sonora das vedações verticais, tanto externas 
quanto internas, em particular de separação da unidade autônoma e áreas comuns, e de separação entre unidades habitacionais autônomas);

o desempenho térmico do edifício proporcionado pelos elementos de vedação vertical, pelas esquadrias e cobertura, considerado um determinado projeto; para uma análise simplificada são consideradas as características térmicas do elemento de vedação (transmitância e capacidade térmica);

odurabilidade e manutenibilidade (definição de Vida Ùtil de Projeto - VUP, de procedimentos de uso e de manutenção inseridos no manual de uso e manutenção do edifício habitacional manuais destinados tanto a áreas privativas como a áreas comuns).

- Questões de durabilidade, relativas à vida útil de projeto e de manutenibilidade precisam ser analisadas e discutidas também nas etapas preliminares de projeto e o detalhamento das suas soluções precisa ser feito antes do início da execução das obras. Os períodos de inspeção e manutenção preventiva devem ser sugeridos no manual do usuário. Podem existir situações que cada material ou componente tenha o seu próprio período de inspeção e eventual substituição. Sugere-se que esse manual seja desenvolvido por partes, coincidentes com as da norma NBR 15575 (2008). Também devem constar no manual, principalmente para as tecnologias de vedações verticais, informações importantes sobre as condições de uso, tais como: fixação de peças suspensas nas paredes, localização das instalações (elétricas e hidráulicas), formas de realizar inspeções e manutenções, eventuais restrições de uso, cuidados necessários com ação de água nas bases de fachadas e de paredes internas de áreas molháveis, entre outras informações pertinentes ao uso da tecnologia.

Portanto, apresenta-se no Quadro 2 um resumo das considerações feitas em relação às etapas e aos produtos do processo de projeto. 0 esquema do processo de projeto (fases, etapas e produtos) adotado segue a representação proposta por Melhado et al. (2005). 
Quadro 2 - Etapas do processo de projeto e seus produtos versus as considerações de desempenho sugeridas para serem feitas em cada uma dessas etapas e produtos

\begin{tabular}{|c|c|c|c|}
\hline \multirow{2}{*}{$\begin{array}{l}\text { 心 } \\
\text { त్ } \\
\text {. }\end{array}$} & \multicolumn{3}{|c|}{ Etapas/Atividades/Considerações de desempenho } \\
\hline & Etapa & Produto da etapa & Considerações de desempenho \\
\hline 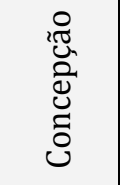 & $\begin{array}{l}\text { Idealização do } \\
\text { produto }\end{array}$ & $\begin{array}{l}\text { Programa de } \\
\text { necessidades e } \\
\text { prioridades }\end{array}$ & $\begin{array}{l}\text { Levantamento dos requisitos de } \\
\text { desempenho (exigências qualitativas) } \\
\text { aplicáveis para o empreendimento } \\
\text { específico }\end{array}$ \\
\hline \multirow{9}{*}{$\begin{array}{l}0 \\
0 \\
.0 \\
0 \\
0 \\
0 \\
0 \\
0 \\
0 \\
0 \\
0 \\
0 \\
0 \\
0 \\
0 \\
0 \\
0 \\
0 \\
0 \\
0 \\
0 \\
0 \\
0\end{array}$} & & & Ratificação dos requisitos de desempenho \\
\hline & $\begin{array}{l}\text { Desenvolvimento } \\
\text { do produto }\end{array}$ & $\begin{array}{l}\text { Estudo } \\
\text { preliminar }\end{array}$ & $\begin{array}{l}\text { Seleção da tecnologia baseada na avaliação } \\
\text { entre benefícios técnicos, de custo e prazo. } \\
\text { Os benefícios técnicos avaliam o potencial } \\
\text { daquela tecnologia em atender aos } \\
\text { requisitos de desempenho pré-definidos }\end{array}$ \\
\hline & \multirow{4}{*}{ Formalização } & \multirow{4}{*}{$\begin{array}{l}\text { Anteprojeto e } \\
\text { projeto pré- } \\
\text { executivo }\end{array}$} & $\begin{array}{l}\text { Discussão e formalização dos critérios de } \\
\text { desempenho (parâmetros quantitativos) }\end{array}$ \\
\hline & & & $\begin{array}{l}\text { Definição dos métodos a serem adotados } \\
\text { para comprovação do atendimento aos } \\
\text { critérios de desempenho (análise de } \\
\text { projetos, resultados de ensaios, experiências } \\
\text { anteriores etc. ) }\end{array}$ \\
\hline & & & $\begin{array}{l}\text { Inclusão das exigências de desempenho e } \\
\text { seus métodos de comprovação nos contratos } \\
\text { com fornecedores }\end{array}$ \\
\hline & & & $\begin{array}{c}\text { Compilação dos resultados de desempenho } \\
\text { da tecnologia específica. Para tecnologias } \\
\text { inovadoras, pode-se recorrer ao DATec; para } \\
\text { tecnologias convencionais, ao banco de } \\
\text { dados existentes, ou buscar seu } \\
\text { desenvolvimento }\end{array}$ \\
\hline & \multirow{3}{*}{ Detalhamento } & \multirow{3}{*}{$\begin{array}{l}\text { Projeto executivo } \\
\text { e projeto para } \\
\text { produção }\end{array}$} & $\begin{array}{l}\text { Detalhamento técnico dos projetos, } \\
\text { considerando as soluções construtivas para } \\
\text { atendimento aos critérios de desempenho }\end{array}$ \\
\hline & & & $\begin{array}{l}\text { Elaboração do projeto para produção, } \\
\text { incluindo procedimentos de execução }\end{array}$ \\
\hline & & & $\begin{array}{c}\text { Desenvolvimento dos manuais de uso e } \\
\text { manutenção do edifício para os diversos } \\
\text { elementos e subsistemas. Nesses manuais } \\
\text { devem constar VUP, períodos e } \\
\text { procedimentos de manutenção para atingir a } \\
\text { VUP } \\
\end{array}$ \\
\hline 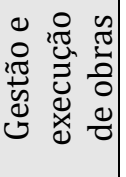 & $\begin{array}{l}\text { Planejamento } \\
\text { para a execução }\end{array}$ & $\begin{array}{l}\text { Execução } \\
\text { conforme projeto } \\
\text { e especificações } \\
\text { técnicas }\end{array}$ & $\begin{array}{l}\text { Preservação das especificações e detalhes } \\
\text { que favorecem o desempenho }\end{array}$ \\
\hline 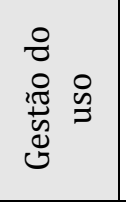 & $\begin{array}{l}\text { Gestão e } \\
\text { manutenção }\end{array}$ & $\begin{array}{l}\text { Gerenciamento } \\
\text { do uso e da } \\
\text { manutenção; } \\
\text { gerenciamento da } \\
\text { operação }\end{array}$ & $\begin{array}{l}\text { Gerenciamento do edifício, considerando o } \\
\text { manual de uso e manutenção }\end{array}$ \\
\hline
\end{tabular}




\section{CONSIDERAÇÕES FINAIS}

Os resultados das análises conduzidas justificam e reforçam a necessidade da incorporação de modificações ao processo de projeto de edifícios habitacionais, para que o edifício como um todo e seus subsistemas específicos sejam projetados também considerando a abordagem de desempenho, de forma a atenderem potencialmente, desde esta etapa, a norma brasileira de desempenho de edifícios habitacionais, a ABNT NBR 15575(2008), partes 1 a 6, ou normas sucedâneas.

Para que as considerações feitas neste artigo sejam integradas ao processo de projeto é preciso que os projetistas tenham conhecimento sobre as questões de desempenho e o incorporador estabeleça também como prioridade $\mathrm{o}$ atendimento aos requisitos de desempenho e à referida norma. Tais requisitos e seus respectivos critérios devem ser discutidos desde a etapa de definição do programa de necessidades do empreendimento.

Os aspectos de durabilidade e manutenibilidade vão permitir análises a respeito de custo ao longo da vida útil de um edifício, além das análises já praticadas de custos iniciais. 0 custo total do edifício ou do empreendimento, além dos custos envolvidos com terrenos e outros itens, é a soma dos custos de projeto, de fabricação, de execução, de operação e de manutenção, podendo-se considerar até os custos futuros de demolição, ou desconstrução, por exemplo. Caso seja possível reciclar ou reutilizar os materiais e componentes, existe um valor final a ser computado; para tanto, será fundamental a definição prévia de períodos de inspeção e troca de materiais, e de procedimentos de operação e manutenção dos edifícios, que serão incorporados ao manual de uso e manutenção do empreendimento.

Outro aspecto importante é a formalização e a solicitação para que fornecedores apresentem dados técnicos sobre seus produtos, pois, sem o conhecimento das características de cada material e componente, bem como do seu comportamento em conjunto, não será possível aferir ou estimar o desempenho pretendido e nem o atendimento à referida norma.

Portanto, o conjunto de normas brasileiras de desempenho de edifícios habitacionais (NBR 15575,2008 ) induz a modificações na forma de projetar e também nas formas de contratação de serviços e de aquisição de produtos.

\section{BIBLIOGRAFIA}

ASSOCIAÇÃO BRASILEIRA DE NORMAS TÉCNICAS - ABNT — NBR 15.575-1. Edifícios habitacionais de até cinco pavimentos - $\quad$ Desempenho Parte 1: Requisitos gerais. São Paulo, 2008. 52p

- NBR 15.575-2: Edifícios habitacionais de até cinco pavimentos - Desempenho Parte 2: Requisitos para os sistemas estruturais. São Paulo, 2008. 30p.

- NBR 15.575-3: Edifícios habitacionais de até cinco pavimentos - Desempenho Parte 3: Requisitos para os sistemas de pisos internos. São Paulo, 2008. 37p.

- NBR 15.575-4: Edifícios habitacionais de até cinco pavimentos - Desempenho Parte 4: Sistemas de vedações verticais externas e internas. São Paulo, 2008. 50p.

- NBR 15.575-5: Edifícios habitacionais de até cinco pavimentos - Desempenho Parte 5: Requisitos para sistemas de coberturas. São Paulo, 2008. 54p..

- NBR 15.575-6:. Edifícios habitacionais de até cinco pavimentos - Desempenho Parte 6: Sistemas hidrossanitários. São Paulo, 28p.

AQUINO, J. Diagnóstico das dificuldades do uso de projeto para produção de vedações verticais. São Paulo, 2005. 184p. Dissertação (Mestrado) - Escola Politécnica, Universidade de São Paulo, São Paulo, 2005

BECKER, R. Implementation of the performance approach in the investigation of innovative building systems. Building and Environment, 37 (2002) 923-931.

CABINET CASSO et Cia. Securité contre l'incendie dans les ERP. Technique de l'ingénierie, revue on line, code C3280, 2004. (Em Francês)

CABINET CASSO et Cia. Securité contre l'incendie dans les IGH. Technique de l'ingénierie, revue on line, 
code C3281, 2002. (Em Francês)

CANADIAN STANDARDS ASSOCIATION - CSA478-95. Guideline on Durability in Buildings, (R2001), pp. 9-17, Canada, 2001.

CLETO, Fabiana da Rocha ; CARDOSO, Francisco Ferreira ; MITIDIERI FILHO, Cláudio Vicente ; AGOPYAN, Vahan. Códigos de práticas: uma proposta de documentos técnicos de referência de boas práticas para a construção de edifícios no Brasil. Revista Ambiente Construído, ANTAC, ISSN 1678-8621, acesso em 22 de novembro de 2011, disponível em http://seer.ufrgs.br/ambienteconstruido/article/view/16822.

CONSTRUÇÃO MERCADO. Orçamento Real. Pini, 59 (2006).

CONSTRUÇÃO MERCADO. Orçamento Real. Pini, 79 (2008).

FRANCE. Réglémentation thérmique RT 2005 (Arrêté du 24 mai 2006 relatif aux caractéristiques thermiques des bâtiments nouveaux et des parties nouvelles de bâtiments 2006). Texto geral do Ministère de l'emploi, de la cohésion sociale et du logement français, disponível em $<$ http://www.legifrance.gouv.fr>, Acesso em novembro de 2011. (Em Francês)

HERNÁNDEZ-MORENO. Integration of Service Life in the Process of Management and Design of Buildings. Management Research and Practice. Vol. 2, Issue 4, December 2010.

INTERNATIONAL STANDARDS ORGANIZATION — ISO 15686-1. Buildings and constructed assets-Service Life Planning, part 1: General Principles. pp. 18-49, Switzerland, 2000

MEISSER, M. Réglementation acoustique des bâtiments. Technique de l'ingénierie, revue on line, code C 3 365, 2005. (Em Francês)

MELHADO, S. B. Gestão, cooperação e integração para um novo modelo voltado à qualidade do processo de projeto na construção de edifícios. 2001. 235p. Tese (Livre-Docência) - Escola Politécnica, Universidade de São Paulo. São Paulo, 2001.

MELHADO, S. B.; SOUZA, A. L. R.; GRILO, L.; MESQUITA, M. J. O processo de projeto e sua gestão. In : Coordenação de projetos de edificações. São Paulo: O Nome da Rosa, 2005. Capítulo 2.

OLIVEIRA, L.A. Metodologia para desenvolvimento de projeto de fachadas leves. Tese (Doutorado) Escola Politécnica, Universidade de São Paulo, São Paulo (2009).

ONO, R. Parâmetros para garantia da qualidade do projeto de segurança contra incêndio em edifícios altos. Ambiente Construído, Porto Alegre, v. 7, n. 1, p. 97-113, jan./mar. 2007.

RIVARD, H., BEDARD, C., HA, K.H., FAZIO, P. Shared conceptual model for the building envelope design process. Building and Environment, 34 (1999)- 175-187.

SOUZA, J. S. Metodologia de Análise e Seleção de Inovações Tecnológicas na Construção de Edifícios: Aplicação para a vedação vertical de gesso acartonado. 2003. 205p. Tese (Doutorado) - Escola Politécnica, Universidade de São Paulo, São Paulo, 2003

UNITED NATIONS ENVIRONMENT PROGRAMME / DIVISION OF TECHNOLOGY, INDUSTRY AND ECONOMICS - UNEP/TIE. Design For Sustainability: A Practical Approach For Developing Economies. Paris, 2007. Disponível em <http:// www.uneptie.fr $>$

VIGAN, J. DICOBAT: Dictionnaire général du bâtiment. Ris-Orangis: Editions Arcature, 1993. 952p. (Em Francês)

YIN, R. K. The case study as a serious research strategy. Knowledge (3), p.97-114, 1981.

\section{DADOS DOS AUTORES}

(i) Pesquisadora do Instituto de Pesquisas Tecnológicas - IPT e docente do Mestrado de Habitação do IPT | São Paulo, Brasil (ii)Professor convidado da Pontifícia Universidade Católica de Minas Gerais e pesquisador III e docente do Mestrado de Habitação do Instituto de Pesquisas Tecnológicas do Estado de São Paulo. | São Paulo, Brasil 